\title{
NATURAL AGEING OF STABILIZED AND UNUSTABILIZED LDPE FILMS USED AS GREENHOUSES COVERING MATERRIALS: ATR- FTIR AND SEM ANALYSIS
}

\author{
Mourad Hamouya ${ }^{1}$, Aicha Mahir ${ }^{2}$, Mohamed Chafik EL Idrissi ${ }^{3}$ \\ ${ }^{I}$ Physics Department, Physics of surfaces and interfaces, Ibn Tofail University, kenitra, Morocco \\ ${ }^{2}$ Physics Department, Physics of surfaces and interfaces, Ibn Tofail University, kenitra, Morocco \\ ${ }^{3}$ Physics Department, Physics of surfaces and interfaces, Ibn Tofail University, kenitra, Morocco
}

\begin{abstract}
This article focuses on the study of both stabilized and unstabilized low-density polyethylene films aged under natural weathering in the middle of Morocco (Sidi Kacem city). The study was undertaken on three samples for each LDPE films: a new sample taken as reference; another exposed to outdoor weathering for one year; and a sample exposed for two years.

The outdoor exposure effects were followed by analysis of the total reflection Fourier transform infrared spectroscopy (ATR$F T I R)$. This technique provides information on the main chemical functions and evaluates the internal causes of natural ageing of our samples. The infrared spectra show the formation of hydroperoxides $-\mathrm{O}-\mathrm{OH}$, carbonyls $>C=O$, aliphatic esters $R-(\mathrm{CO})-\mathrm{O}-\mathrm{R}$, ether $\mathrm{R}-\mathrm{O}-\mathrm{R}$, vinyl $\mathrm{C}=\mathrm{C}$, vinylidene $>\mathrm{C}=\mathrm{CH}_{2}$ and trans-vinylene $\mathrm{RHC}=\mathrm{CRH}$ in the amorphous regions. These compounds lead to initiate the mechanism of photo-oxidation of the unstabilized LDPE samples. Therefore, the increase in the formation of oxidation products into the aged samples (LDPEUS) indicates an accelerated degradation of these latter on climatic factors (UV, O2, humidity, rain ...). The UV stabilizer (free radicals scavengers) added to the formulation of LDPE films can delay the attack of the amorphous phase and prevent the formation of compounds that can cause and accelerate photo-oxidation. The results obtained by the infrared have been confirmed by observing the morphology of the samples with scanning electron microscopy technology (SEM).
\end{abstract}

Keywords: LDPE, Photo-oxidation, Natural ageing, UV stabilizer, ATR-FTIR, SEM

\section{INTRODUCTION}

Polyethylene is the most widespread polymer in the world. It belongs to the family of the polyolefin. The annual production is approximately at 80 million metric tons in 2008 [1]. Precisely, low-density polyethylene is widely used in greenhouses as covering material due to its dielectric properties combined with long durability [2], excellent chemical resistance $[3,4,5]$, good resistance to cracking, low permeability to water vapor [6], low cost and easy manufacture $[2,7]$.

The exposure of low-density polyethylene film under natural weathering is giving rise to degradation effects. However, weathering is commonly defined as the undesirable change produced by outdoor exposure [8]. The ageing of lowdensity polyethylene results in a slow, often irreversible deterioration of the chemical properties stemming from its own instability or the effect of the environment [9]. Thus, external environment factors such as leaching by rainwater, the ultraviolet radiation (UV) and seasonal variations in temperature can cause chemical degradation of polyethylene and its weakening [10].

This work can be added to many studies have been focused on the photo-degradation of low-density polyethylene films in order to understand their mechanisms. These mechanisms can be resulted by chain-scission or crosslinking the primary structure of polymer films $[11,12]$. The study of the photo-oxidation of low density polyethylene has been focused on the exposure of both commercial greenhouses to weathering conditions (outdoor) in the middle of Morocco (Sidi Kacem city). Thus, the study was undertaken on three samples for each agricultural greenhouse: a new sample taken as reference; another sample exposed to weathering for one year; and a sample exposed for two years.

The photo-degradation of low-density polyethylene film through the natural ageing was followed by testing of the attenuated total reflection Fourier transform infrared spectroscopy (ATR-FTIR). This technique provides information on the main chemical functions and evaluates the internal causes of natural ageing of our samples. Yet, the analysis by scanning electron microscopy (SEM) can reveal comparisons of the surface morphology of the samples.

\section{EXPERMENTAL}

\subsection{Material}

The commercial samples kinds (one stabilized and the other unstabilized) are supplied by the company MICATEXE (Company Production of Agricultural Films Morocco). They 
have densities known between 0,92 and 0,98 g.cm ${ }^{-3}$, thickness between 180-200 microns and weight between $165,5-176,5$ g.m ${ }^{-2}$. The average temperature of the production order is $200{ }^{\circ} \mathrm{C}$. Two unaged samples were analyzed by ATR-FTIR spectroscopy and SEM served as reference.

\subsection{Natural ageing exposure}

The four kinds of samples (stabilized and unstabilized) were exposed to natural weathering. Two were exposed for one year and the other two were exposed for two years. The exposure of these samples of the low-density polyethylene under natural weathering was carried out at the roof of a building in Sidi Kacem city of Morocco.

\subsection{Attenuated Total Reflection Fourier Transform}

\section{Infrared Spectroscopy}

The ATR-FTIR spectroscopy is a very sensitive technique used for surface analysis. The advantage is the possibility of obtaining the spectra directly from the sheet without any further sample preparation.

The spectroscopy FT-IR is a Bruker Tensor 27 system and is installed in the laboratory spectroscopy measurements and research center of the University Ibn Tofail in Kenitra. It is equipped with a room temperature DTGS (deuterated triglycine sulfate) detector, another MCT (mercury cadmiumtelluride) detector for use with the more IR-beam absorbing special samples, mid-IR source from 4000 to $400 \mathrm{~cm}^{-1}$, and a $\mathrm{KBr}$ beam splitter. The MCT detector is about 10 times more sensitive than the DTGS detector. The sample cell in the FT-IR is a pike Miracle single-bounce attenuated total reflectance (ATR) cell equipped with a $\mathrm{ZnSe}$ ( $\mathrm{ZnSe}$ absorbs strongly below $650 \mathrm{~cm}^{-1}$ ) single crystal. This system is free to use with maximum resolution $1 \mathrm{~cm}^{-1}$ [13].

The sample of low-density polyethylene is placed directly on the small crystal spot and the arm rotated over and turned down to press the sample down onto the crystal face to get better contact. The IR beam penetrates about $60 \mu \mathrm{m}$ into the sample. The OPUS (Optical User Software) is the Bruker data collection and analysis program for the Tensor 27 FTIR [13].

\subsection{Degree of crystallinity}

The infrared spectroscopy is a technique used to determine the rate of crystallinity. The empirical equation proposed by Zerbi et al.'s used to evaluate the rate of crystallinity [14]:

$$
X_{c,(\%)}=\left(1-\frac{\left(\left(I_{a}-I_{b}\right) / 1.233\right)}{\left(I_{a}+I_{b}\right)}\right) \times 100
$$

Where $I_{a}$ and $I_{b}$ are the absorbances of the peaks at 721 and $729 \mathrm{~cm}^{-1}$, respectively. The constant 1.233 corresponds to the relations of the intensity bands of fully crystalline polyethylene.

\subsection{Index degradation products}

\subsubsection{Index of vinyl}

The amount of vinyl products can give the vinyl index calculation from the measurement of peak area $909 \mathrm{~cm}^{-1}$ and normalized to a peak at $2912 \mathrm{~cm}^{-1}$, which corresponds to asymmetric stretching vibration of $\mathrm{CH}_{2}$ functional group that is stable to photo-degradation. The vinyl index is calculated from the following formula [15]:

$$
I_{\text {vinyl }}=\mathcal{A}_{909 \mathrm{~cm}^{-1}} / \mathcal{A}_{2912 \mathrm{~cm}^{-1}}
$$

\subsubsection{Index of carbonyl}

The relative absorbance of the carbonyl group is expressed by the carbonyl index. Latter is defined to describe the formation of carbonyl oxidation products [16].

$$
I_{\text {carbonyl }}=\mathcal{A}_{C=O} / \mathcal{A}_{2912 \mathrm{~cm}^{-1}}
$$

Where $\mathcal{A}_{C=O}$ and $\mathcal{A}_{2912 \mathrm{~cm}^{-1}}$ are the peak area of the carbonyl group was determined in the range of 1800-1670 $\mathrm{cm}^{-1}$ and the reference, respectively.

\subsection{Scanning Electron Microscopy}

The observation of the samples in cutting or in surface was realized on a device of method ESEM with a gas pressure in the room being able to go until $26 \mathrm{~m}$ bar. It is also the only allowing microscope to work in three methods of different emptiness: high vacuum (10-6 mbar), low vacuum $(0,1-1,33$ mbar), and environmental (1,33-26 mbar). And for each of these methods a detector of the secondary electrons that furnishes non-drivers without any preparation, it also allows to observe in a dynamic manner of the materials under a given environment (pressure, temperature, gas composition). It remains topographic on the sample. The method ESEM eliminates totally the effects of loads and allows the observation of samples non-drivers without any preparation. Equipped with a complete system of microanalyses $\mathrm{X}$ (Detector EDX-EDAX) and of a detector of the electrons retro diffused, it allows giving the chemical composition of this $[17,18]$.

\section{RESULTS AND DISCUSSION}

\subsection{Attenuated Total Reflection Fourier Transform}

\section{Infrared Spectroscopy}

The infrared spectra of two new stabilized and unstabilized samples are shown in Fig-1. This result indicates the occurrence of the main vibration modes in the form of absorption bands that are attached to organic groups. These spectra show the presence of two regions: The first frequency is greater than $1500 \mathrm{~cm}^{-1}$ and which relates to angular bending vibrations in the plane and out of plane. The second frequency is less than $1500 \mathrm{~cm}^{-1}$ and which relates to stretching vibrations [19]. 


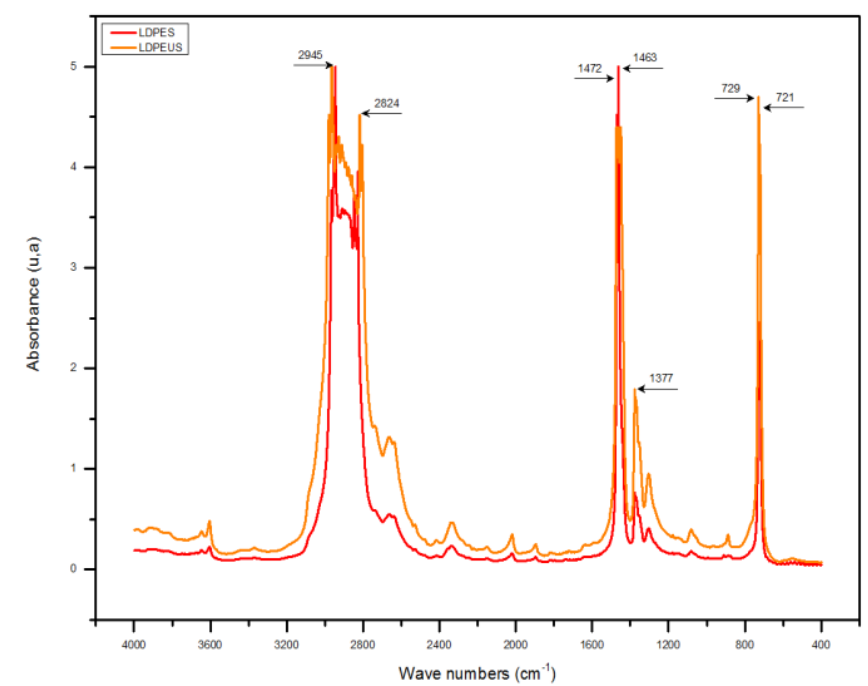

Fig-1: Infrared spectra of new LDPES and LDPEUS films

The infrared spectra show the presence of two bands with frequencies 2945 and $2824 \mathrm{~cm}^{-1}$ corresponding to the stretching vibration of asymmetric and symmetric $\mathrm{C}-\mathrm{H}$ bond of the methylene $\mathrm{CH}_{2}$ group [20].

The two peaks of the doublet 1472 and $1463 \mathrm{~cm}^{-1}$ are attributed to the bending deformation of the methylene $\mathrm{CH}_{2}$ groups in crystalline and amorphous phases respectively [21].

The two intense peaks as a doublet with the frequencies 729 and $721 \mathrm{~cm}^{-1}$ are ascribed to the rocking deformation of the methylene $\mathrm{CH}_{2}$ groups in crystalline and amorphous domains respectively $[21,22]$.

The peak at $1377 \mathrm{~cm}^{-1}$ with a weak intensity is assigned to $\mathrm{CH}_{3}$ symmetric deformation crystalline [23, 24].

The spectra of the stabilized and unstabilized LDPE films aged under natural weathering for the one and two years are shown in Figs-2 and 3. We observe the emergence of new bands that have been considered as a starting point of the natural ageing process.

For the stabilized LDPE samples (Fig-2) we observe:

- Two peaks with a very weak intensity: one at $888 \mathrm{~cm}^{-1}$ is assigned to vinylidene $>\mathrm{C}=\mathrm{CH}_{2}$ groups and the other at $831 \mathrm{~cm}^{-1}$ corresponding to the vinyl $\mathrm{R}_{2} \mathrm{C}=\mathrm{CHR}$ groups $[25,26,27,28]$. These unsaturations are also visible to $1635 \mathrm{~cm}^{-1}$.

- Formation of the massive bands from 1200 to $1000 \mathrm{~cm}^{-}$ 1; particularly, two peaks around 1080 and $1045 \mathrm{~cm}^{-1}$ are attributed to the stretching vibration of $\mathrm{C}-\mathrm{O}$ bond, this latter belongs to ether $\mathrm{R}-\mathrm{O}-\mathrm{R}$ and alcohol $\mathrm{RCH}_{2}$ $\mathrm{OH}$ groups [19, 29].

For the unstabilized LDPE samples (Fig-3) we observe:

- Two extensive bands one at $3530 \mathrm{~cm}^{-1}$ and the other at $3441 \mathrm{~cm}^{-1}$, respectively assigned to free and associated hydro-peroxides (O-O-H) groups [21, 28, 30].
A broad band at $3369 \mathrm{~cm}^{-1}$ assigned to all of the hydroxyl $(\mathrm{O}-\mathrm{H})$ groups [28].

- Two peaks of high intensity at 1712 and $1733 \mathrm{~cm}^{-1}$ were attributed to $\mathrm{C}=\mathrm{O}$ stretching vibration of ketone and aliphatic esters respectively [31, 32]; ester group presents additional $\mathrm{C}-\mathrm{O}$ bond confirmed by the presence of the peak at $1180 \mathrm{~cm}^{-1}[31,32]$.

- Important massive bands between 1000 and $1200 \mathrm{~cm}^{-1}$; particularly, two peaks 1083 and $1180 \mathrm{~cm}^{-1}$ are attributed to stretching vibrations of the $\mathrm{C}-\mathrm{O}$, and belong to ether and aliphatic esters groups respectively $[19,29,33]$.

- $\quad$ Formation of the massive bands between 850 and 1000 $\mathrm{cm}^{-1}$; specifically, Two peaks 994 and $909 \mathrm{~cm}^{-1}$ corresponding to the vinyl $\mathrm{RCH}=\mathrm{CH}_{2}$ groups, another peak rises around $962 \mathrm{~cm}^{-1}$ attributed to trans-vinylene $\mathrm{RHC}=\mathrm{CRH}$ groups and finally, one peak at $888 \mathrm{~cm}^{-1}$ attributed to vinylidene $>\mathrm{C}=\mathrm{CH}_{2}$ groups $[25,26,27$, 28]. These unsaturations are also visible to $1641 \mathrm{~cm}^{-1}$.

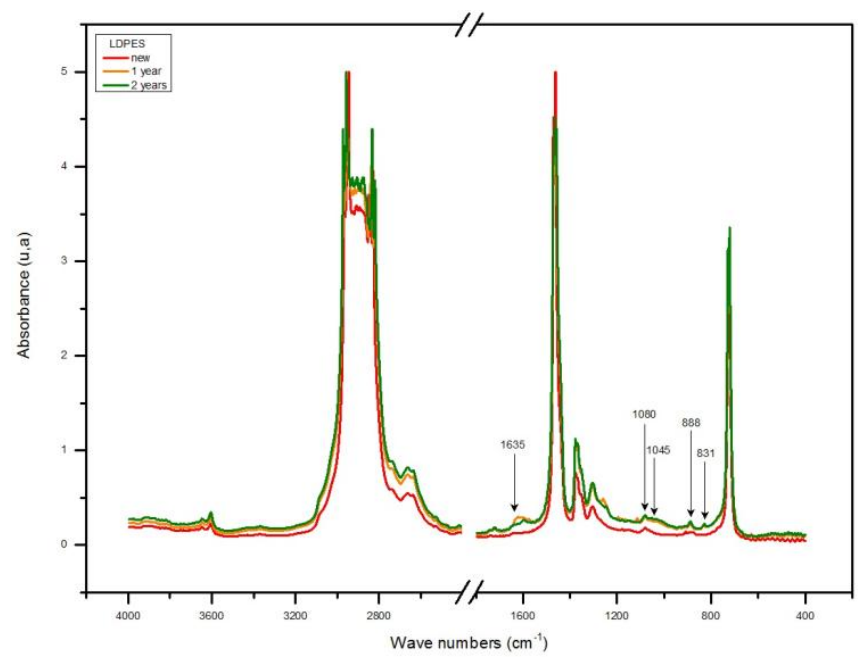

Fig-2: Infrared spectra of LDPES samples after exposure to natural weathering

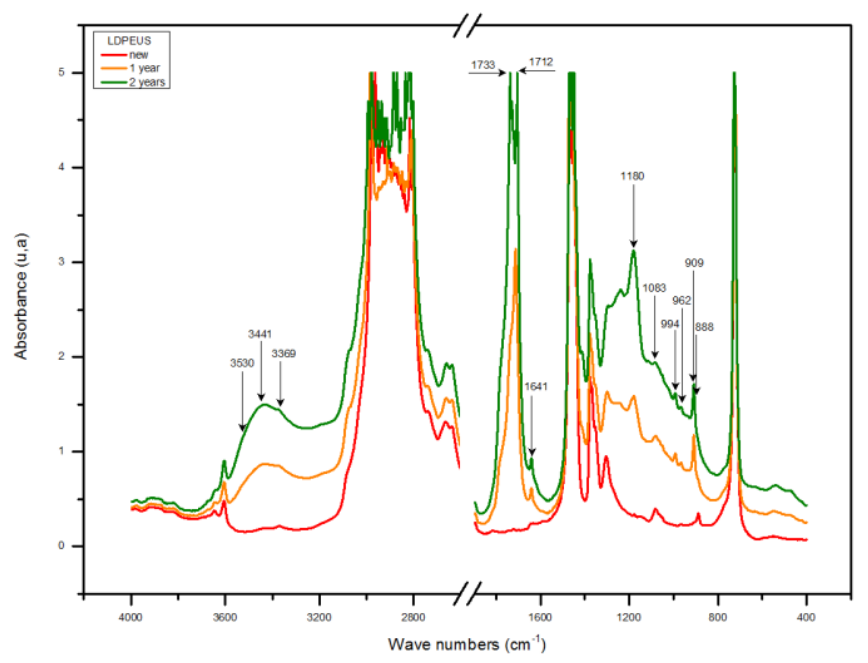

Fig-3: Infrared spectra of LDPEUS samples after exposure to natural weathering

The absence of the bands attributed to hydroperoxides groups in the infrared spectra of stabilized samples (Fig-2) 
can relate to the presence of hydroperoxides decomposers associated with phenolic antioxidants. The compounds most commonly used to decompose hydroperoxides are trivalent phosphites. We also decompose hydroperoxides (react 1); the phosphites could appear as reducing peroxyl (react 2) and alkoxyl (react 3) radicals [33, 34].

$\mathrm{POOH}$

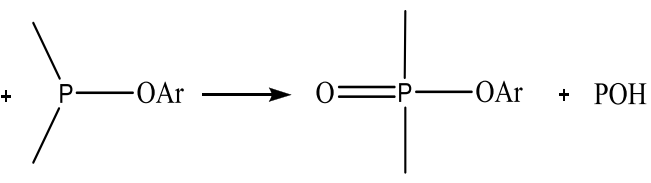<smiles>CP(C)O[Ga]OP(C)(C)=O</smiles><smiles>CP(C)O[Ga]P(C)[Po]</smiles>

However, phenolic antioxidants (Butylated hydroxytoluene (BHT)) are most widely used to capture the free radicals [33]. The reaction equation (react 4) is given as follows [34, 35]. According to [33], the phenoxy radicals formed are stabilized by isomerism.

$$
\mathrm{AH}+\mathrm{POO} \longrightarrow \dot{\mathrm{A}}+\mathrm{POOH}
$$

The appearance of bands attributed to hydroperoxides (Fig. 3) results in the absence of decomposers of hydroperoxides associated with phenolic antioxidants. The preferential oxidation of the amorphous phase relative to the crystalline phase is a result of the higher diffusion of oxygen within it. The hydroperoxides are extremely photo-labile. They absorb UV radiation and initiate photo-oxidation [36, 37]. This priming can cause weakness of the initial split $\mathrm{O}-\mathrm{O}$ bond $\left(\mathrm{E}_{\mathrm{d}}\right.$ $=176 \mathrm{~kJ} \mathrm{~mol}^{-1}[38]$ ) in hydroperoxides (reacts 5-7) $[39,40]$.

$$
\begin{aligned}
& \mathrm{ROOH} \stackrel{\mathrm{hv}}{\longrightarrow} \mathrm{RO}+\dot{\mathrm{OH}} \stackrel{\mathrm{RH}}{\longrightarrow} \dot{\mathrm{R}}+\mathrm{H}_{2} \mathrm{O} / \mathrm{ROH} \\
& \mathrm{R}+\mathrm{O}_{2} \longrightarrow \mathrm{RO}_{2} \\
& \mathrm{RO}_{2}+\mathrm{RH} \longrightarrow \mathrm{ROOH}+\dot{\mathrm{R}}
\end{aligned}
$$

The free-radical products can then attack adjacent sechydroperoxides sites to generate new sec-peroxyl radicals [28] (react 8).

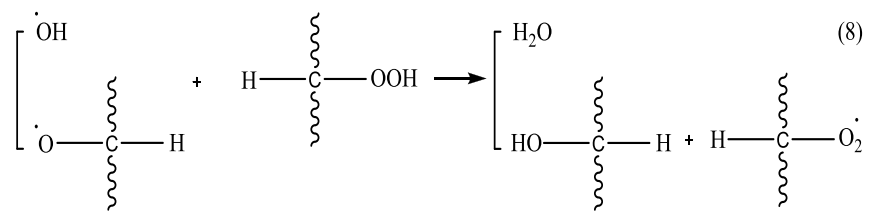

The results presented in Table-1 show a significant increase in the index of carbonyl compounds for unstabilized greenhouses. This increase results from the self-reactivity of peroxyl radicals (react 9) produced from the split of hydroperoxides in the presence of oxygen $[41,28]$ (react 6). Therefore, hydroperoxides are precursors of carbonyl species (ketone) and alcohols.

Table-1: Index vinyl and carbonyl of the different samples LDPES and LDPEUS

\begin{tabular}{|c|c|c|c|}
\hline $\begin{array}{c}\text { Types LDPE } \\
\text { films }\end{array}$ & $\begin{array}{c}\text { Exposure } \\
\text { times }\end{array}$ & $\begin{array}{c}\text { Index } \\
\text { vinyl }\end{array}$ & $\begin{array}{c}\text { Index } \\
\text { carbonyl }\end{array}$ \\
\hline \multirow{3}{*}{ LDPES } & New & 0.032 & 0.022 \\
\cline { 2 - 4 } & One year & 0.140 & 1.895 \\
\cline { 2 - 4 } & Two years & 0.205 & 2.468 \\
\hline \multirow{3}{*}{ LDPEUS } & New & 0.030 & 0.055 \\
\cline { 2 - 4 } & One year & 1.261 & 8.725 \\
\cline { 2 - 4 } & Two years & 3.850 & 12.185 \\
\hline
\end{tabular}

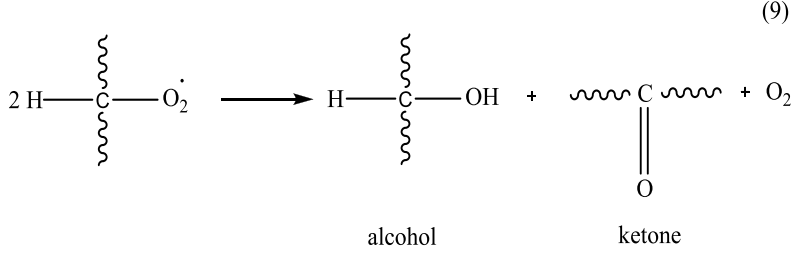

Therefore, the alcohol produced in the above reaction can be attacked to give an alkoxyl [37, 42] (react 10); then it can be transformed into alko-pyroxyl in the presence of atmospheric oxygen. The alkoxyl can react with another peroxyl radical to give a ketone [28] (react 11).

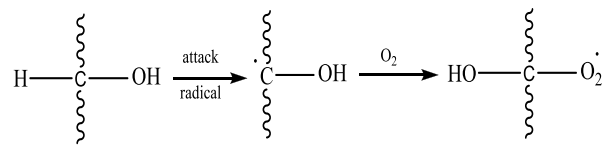

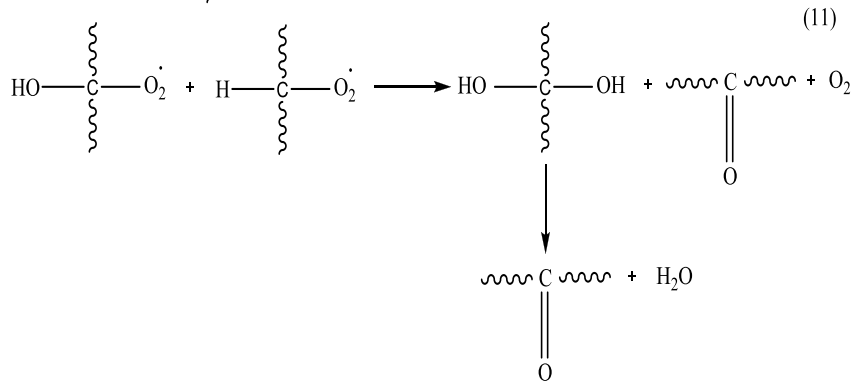

The increase in the index of vinyl compounds is explained by the photolysis of ketones according to the mechanism of Norrish II. This mechanism (photo-cleavage of ketones) gives vinyl compounds (reacts 12, 13) [28]. Norrish type I cleavage will also destroy the ketone groups but is much slower than the type II process for backbone ketones [43, 44]. The photolysis of ketones according to the Norrish I give alkyl radicals. 
<smiles>C=CCC(=O)CCCCC(=O)CCC(=O)CC</smiles>

In addition to the photolysis of hydroperoxides and carbonyl compounds, other priming is possible of the photo-oxidation resulting from transfer of the charges complexes caused by the presence of catalytic residues or also ozone. Indeed, ozone photolysis by UV radiation (react 14) leads to very reactive species such as singlet oxygen $\left({ }^{1} \mathrm{O}_{2}\right)$. It reacts directly with double bonds and leads to the rupture of chains (react 15) [45].

$$
\mathrm{O}_{3} \stackrel{\mathrm{hv}}{\longrightarrow}\left[\mathrm{l}_{2}\right]^{*}+1 / 20
$$<smiles>C#CC=CCCC(O)C=C</smiles>

Therefore, for LDPEUS we described the increase of $7.26 \%$ the degree of crystallinity after two years (Table.2).This increase due to the molecular chain scission according to the mechanism of Norrish II. Thus, the photo-oxidation makes the amorphous part freer and mobile for recrystallization [46]. However, for LDPES we have a small increase of $1.74 \%$ the degree of crystallinity due to the molecular chain scission according to the Norrish I greater than the Norrish II.

Table-2: Crystallinity of the different samples LDPES and LDPEUS

\begin{tabular}{|c|c|c|}
\hline $\begin{array}{c}\text { Types LDEP } \\
\text { films }\end{array}$ & $\begin{array}{c}\text { Exposure } \\
\text { times }\end{array}$ & $\begin{array}{c}\text { Degree of crystallinity } \\
\%\end{array}$ \\
\hline \multirow{4}{*}{ LDPES } & New & 61.60 \\
\cline { 2 - 3 } & One year & 62.70 \\
\cline { 2 - 3 } & Two years & 63.34 \\
\hline \multirow{4}{*}{ LDPEUS } & New & 65.70 \\
\cline { 2 - 3 } & One year & 69.47 \\
\cline { 2 - 3 } & Two years & 72.96 \\
\hline
\end{tabular}

The formation of hydroperoxides $\mathrm{O}-\mathrm{OH}$, carbonyl $\mathrm{C}=\mathrm{O}$, vinyl $\mathrm{C}=\mathrm{C}$ and trans-vinylene $\mathrm{RHC}=\mathrm{CRH}$ groups (band at $962 \mathrm{~cm}^{-1}$ ) leads to initiate the mechanism of photodegradation of the LDPEUS in a way more advanced than the LDPES. However, the UV stabilizer added to the formulation of LDPE can delay the attack of the amorphous phase and prevent the formation of compounds (hydroperoxides and carbonyls) that can cause and accelerate photo-oxidation.

\subsection{Scanning Electron Microscopy}

The micrographs of scanning electron microscopy (SEM) of two low-density polyethylenes are shown in Fig- 4-9. These show a difference between the morphology of the samples during the natural weathering exposure. We observe the presence of some white spots due to the existence of some vacuum from the liberation of gas during the treatment. Yet, the micrographs can show that the surface of the aged unstabilized LDPE samples is attacked more than the stabilized LDPE samples. This is explained by the increase in the amount of absorbed ultraviolet radiation and increased oxygen diffusion in the samples. Thus, the change in temperature, humidity and rainfall are climatic parameters capable of altering the surface morphology of the samples. These morphologies are a consequence of the increase in photo-oxidation reactions that brings breaking of chemical bonds of the macromolecular backbone of polymer.

Moreover, the existence of dust and air pollutants can affect the mechanism of degradation of the polymer surface. These results show that the unstabilized LDPE films undergo a remarkable degradation of climatic factors $\left(\mathrm{UV}, \mathrm{O}_{2}\right.$, humidity ...), which confirms the results obtained by infrared spectroscopy.

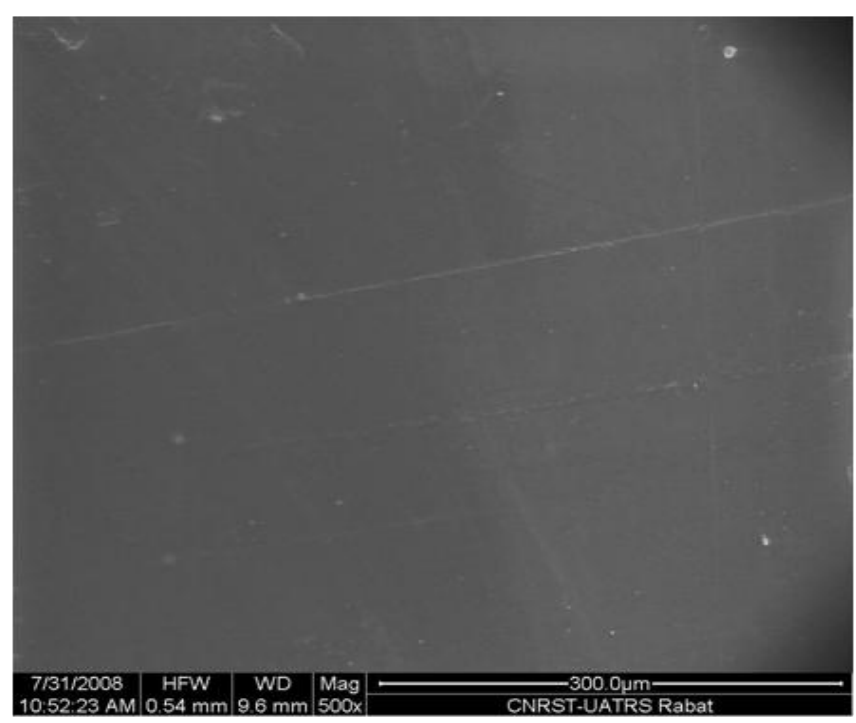

Fig-4: SEM micrograph of virgin LDPES sample 


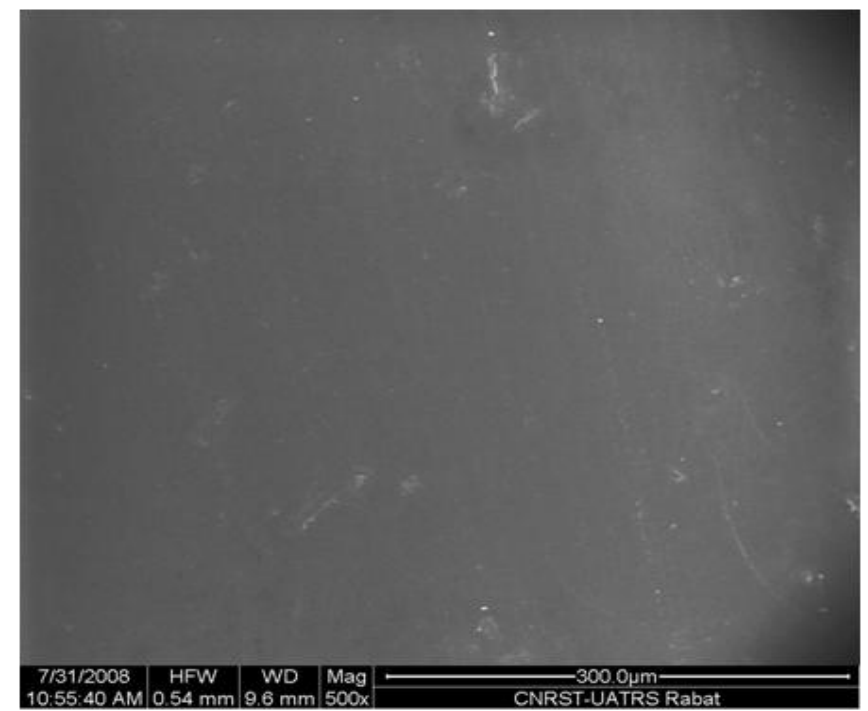

Fig-5: SEM micrograph of LDPES sample after one year

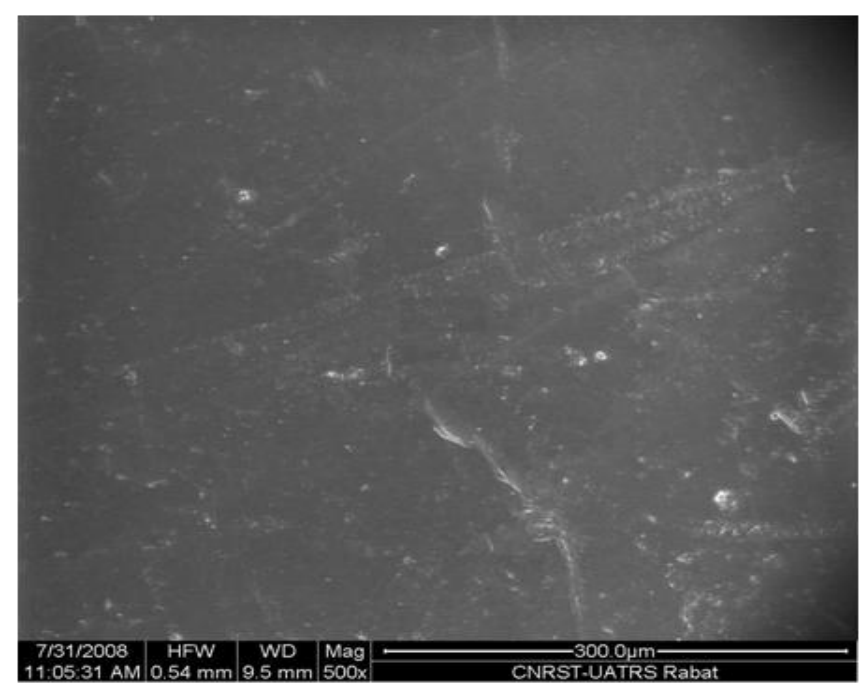

Fig-6: SEM micrograph of LDPES sample after two years

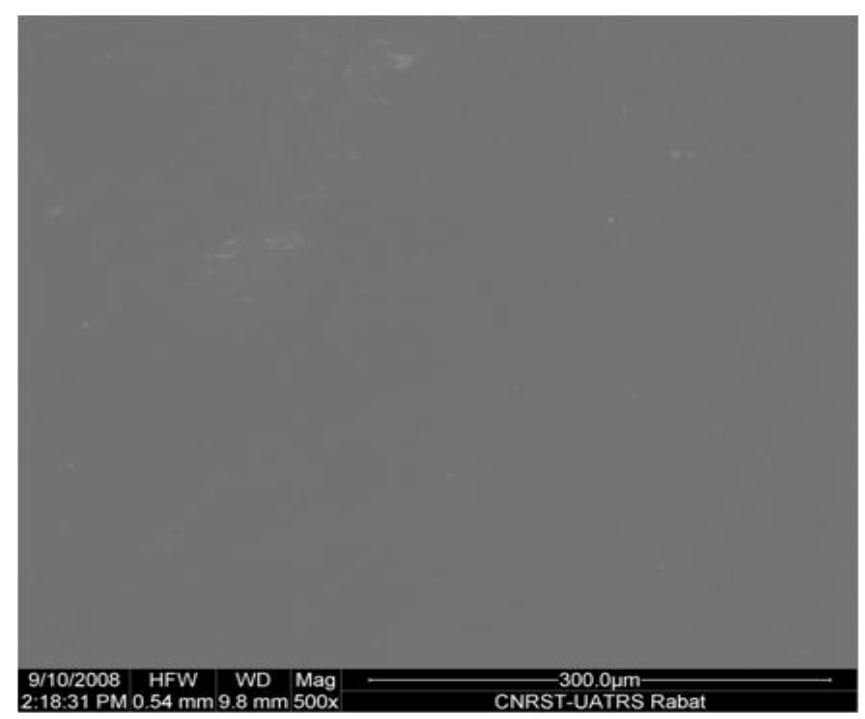

Fig-7: SEM micrograph of virgin LDPEUS sample

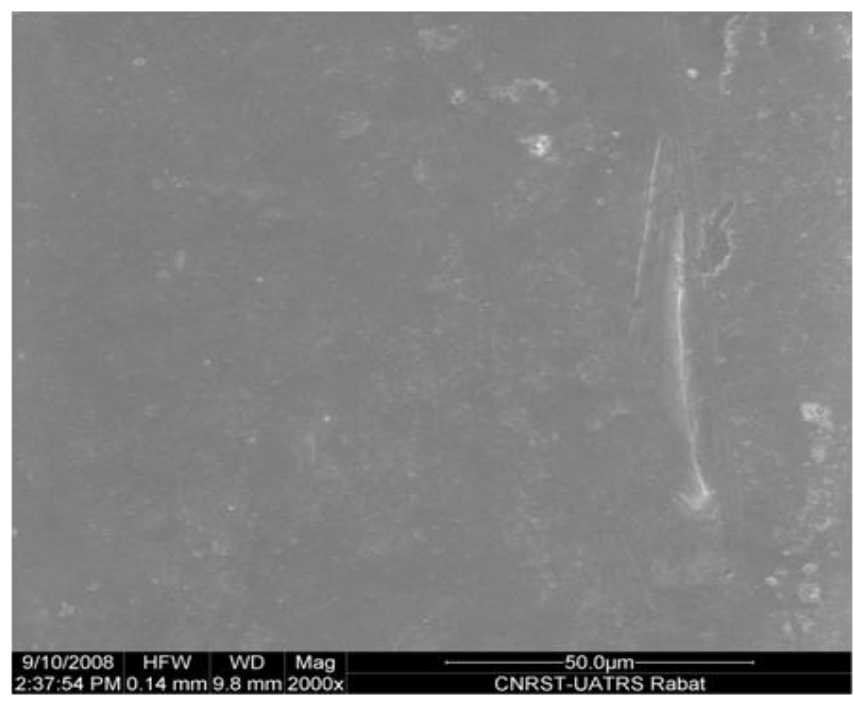

Fig-8: SEM micrograph of LDPEUS sample after one year

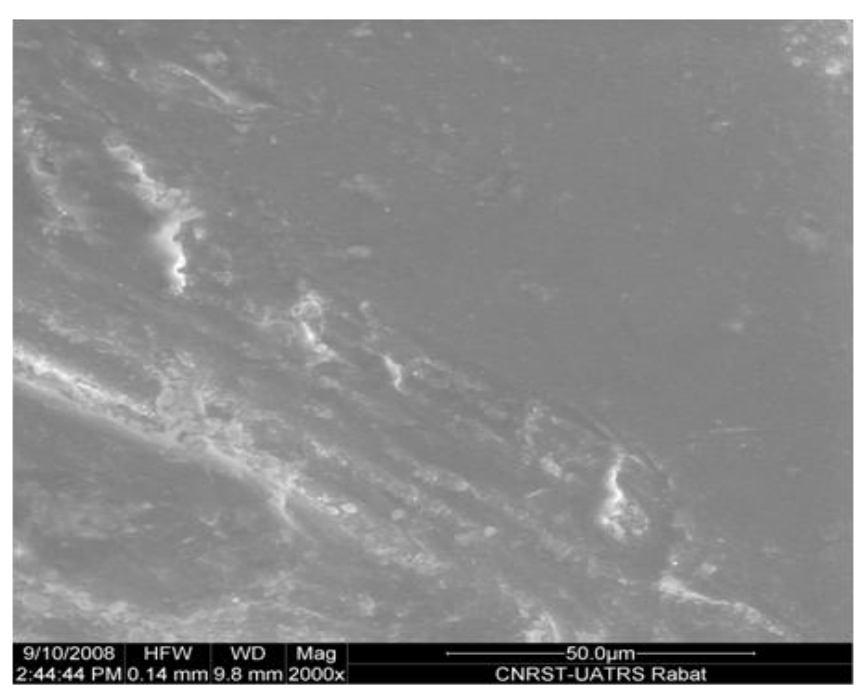

Fig-9: SEM micrograph of LDPEUS sample two years

\section{CONCLUSION}

The ATR-FTIR and scanning electron microscopy (SEM) were used to study the natural ageing of low-density polyethylene greenhouses covering films.

The study by infrared analysis allowed comparisons between the spectra of three samples for each commercial greenhouses (stabilized and unstabilized) to identify different chemical groups of low density polyethylene. This analysis shows the formation of hydroperoxides $-\mathrm{O}-\mathrm{OH}$, carbonyls $>\mathrm{C}=\mathrm{O}$, aliphatic esters $\mathrm{R}-(\mathrm{CO})-\mathrm{O}-\mathrm{R}$, ether $\mathrm{R}-\mathrm{O}-\mathrm{R}$, vinyl $\mathrm{C}=\mathrm{C}$, vinylidene $>\mathrm{C}=\mathrm{CH}_{2}$ and trans-vinylene $\mathrm{RHC}=\mathrm{CRH}\left(962 \mathrm{~cm}^{-1}\right)$ in the amorphous regions. These compounds lead to initiate the mechanism of photooxidation of the unstabilized LDPE samples. The preferential oxidation of the amorphous phase relative to the crystalline phase is a result of the higher diffusion of oxygen within it. The peaks around this latter phase are due to oxidation processes. 
Photo-oxidation is generally considered to be a result of oxidative processes in the amorphous regions, which change the primary structure of a polymer by chain-scission or crosslinking [47, 48]. The increase in the intensity of the carbonyl $>\mathrm{C}=\mathrm{O}$ band $\left(1712 \mathrm{~cm}^{-1}\right)$ due to the accumulation and decomposition of hydroperoxides compounds were formed during outdoor exposure. Thus, the increase in the intensity of the vinyl compounds is explained by the photolysis of ketones according to the mechanism of Norrish type II.

Absorption of a photon of total solar radiation can activate a particular bond or group in a macromolecule. The most deleterious part of total solar radiation is the ultraviolet (UV) radiation (range between 290 and $400 \mathrm{~nm}$ ) which may be the most important factor in the degradation of polymers used for outdoor purposes [49]. The UV stabilizer (free radicals scavengers) added to the formulation of LDPE films can delay the attack of the amorphous phase and prevent the formation of compounds that can cause and accelerate photo-oxidation.

Therefore, the increase in the formation of oxidation products into the aged samples (LDPEUS) indicates an accelerated degradation of these latter on climatic factors (UV, O2, humidity, rain ...). The results obtained by the infrared have been confirmed by observing the morphology of the samples with scanning electron microscopy technology.

\section{ACKNOWLEDGEMENTS}

Authors would like to acknowledge Prof. CEL .Mohamed for the important contribution in infrared measurement of the polyethylene.

\section{REFERENCES}

[1] Otto G, Piringer, Baner AL. Plastic packaging: interactions with food and pharmaceuticals. WileyVCH, 2nd ed, 2008. P. 32.

[2] Trotignon JP, Piperaud M, Verdu J, Dobraczynski A. Précis de matières plastiques. Paris, $5^{\text {éme }}$ ed Nathan, Paris, 1991. P. 27-42.

[3] Nalwa HS. Handbook of low and high dielectric constant Materials and their applications-materials and processing, v.1. Academic, SanDiego. 1999.

[4] Bartnikas R, Eichhorn RM. Engineering dielectrics. v.II A. ASTM Publications. Philadelphia. 1983.

[5] Munaro M, L. Akcelrud L. Correlations between composition and crystallinity of LDPE/HDPE blends, J Polym Res 2008 15:83-88.

[6] Füzessery S. Polyéthylène basse densité. No. A 3310. 1996. P. 7.

[7] ISO-1872-1. Plastic - Polyethylene (PE) moulding and extrusion materials- Part1: Designation system and basis for specifications. 1993.

[8] Feldman D. J Polym Enviro, Vol. 10, No. 4. 2002. P. 163-173.
[9] Kaloustin J, Antonetti P, Berrada A, Claire Y, Perichaud A. Therm Anal 1998. P. 52, 327.

[10] Hamid SH. Handbook of polymer degradation. CRC, 2000.

[11] Rabek FJ. Photodegradation of Polymers. Phys Charact Appl. Berlin: Springer, 1996.

[12] Liu M, Horrocks AH, Hall ME. Correlation of physicochemical changes in UV-exposed LDPE films containing various UV stabilizers. Polym Degrad Stab 1995; 49: 151-161.

[13] Bruker Tensor 27 FT-IR v 1.1: Introduction and OPUS Data Collection Program. P. 4-8.

[14] Zerbi G, Gallino G, Del Fanti N, Baini L, Structural depth profiling in polyethylene films by multiple internal reflection infrared spectroscopy. Polymers, 30(12):2324-2327.

[15] Stark NM, Matuana LM, Surface chemistry changes of weathered HDPE/wood-flo flour composites studied by XPS and FTIR spectroscopy. Polym Degrad Stab 2004; 86(1):1-9.

[16] Stark NM, Matuana LM, Characterisation of weathered wood-plastic composite surface using FTIR spectroscopy, contact angle, and XPS. Polym Degrad Stab 2007; 92(10): 1883-1890

[17] Rjeb M, Labzour A, Rjeb A, Sayouri S, ElIdrissi M.C, Massey S, Adnot A, Roy D. Condens Matter 2004;5(2):168-172.

[18] Peterson JD, Vyazovkin S, Wight CA, Condens Matter 2001; 6:202.

[19] Giasson R. Spectroscopie infrarouge. CHM 1312. 2010. P. 17-18, 23-28.

[20] Dalibart M, Servant L., Spectroscopie infrarouge. 2009. P. 5-7, 2854

[21] Yucheng Fu, Loong-Tak L. Polym Test 2012; 31(1):56-67.

[22] Feuilloley P, César G, Benguigui L, Grohens Y, Pillin I, Bewa H, Lefaux S, Jamal M, Polym Enviro, Vol. 13, No. 4. 2005. P. 349-355.

[23] Gulmine JV, Janissek PR, Heise HM, Akcelrud L. Polym Test. 2002; 31:557-563.

[24] Oldak D, Kaczmarek H, Buffeteau T, Sourisseau C. Mate Sci 2005; 40:4189-4198.

[25] Costa L, Luda MP, Trossarelli L. Ultra high molecular weight polyethylene II.Thermal and photo-oxidation. Polym degrade stab 1997; 58(1/2):41-54.

[26] Teissedre G, Pilichowski JF, Chmela S, Lacoste J. Ageing of epdm- i: Photoand thermal stability of epdm hydroperoxides. Polym Degrad Stab 1996; 53:207-215.

[27] Sebaa M, Servens C, Pouyet J. Natural and artificial weathering of low density polyethylene (LDPE): calorimetric analysis. Appl Polym Sci 1993; 47:1897-1903.

[28] Lacoste J, Carlsson DJ, Falicki S, Wiles DM. Polyethylene hydroperoxides decomposition products. Polym degrad stab1991; 34(1/3):309323.

[29] Boulos Y, Dehbi A, Hamou A, Saiter J. M. Natural ageing of tri-layer polyethylene: Evolution of 
properties and lifetime in North Africa region. Mater Des 2008; 29:2017-2022.

[30] Gugumus F. Thermooxidative degradation of polyolefins in the solid state: Part 5. Kinetics of functional group formation in PE-HD and PE-LLD. Polym degrad stab1997; 55(1):21-43.

[31] Stuart BH, Infrared spectroscopy: Fundamentals and Applications. England: British Library, 2004.

[32] Gulmine JV, Janissek PR, Heise HM, Akcelrud L. Polym Degrad Stab 2003; 79:385-397.

[33] Zweifel H, Maier RD, Schiller M. Plastics additives handbook. Munich: Carl Hanser Verlag, $6^{\text {th }}$ Ed, 2001.

[34] Schwetlick K, Habicher WD. Polymer Durability. American Chemical Society, 1996.

[35] Pospisil S, Nespurek J. Chain-breaking stabilizer in polymers: the current status. Polym Degrad Stab 1995; 49: 99-110.

[36] Allen NS, McKellar JF. Photodegradation and stabilization of commercial polyolefins. Chemical Society Reviews, 1975; 4(4):533-547.

[37] Carlsson DJ, Wiles DM. The photodegradation of polypropylene films. II. Photolysis of ketonic oxidation products. Macromolecules, 1969; 2(6):587-597.

[38] BensonSW. Kinetics of Pyrolysis of Alkyl Hydroperoxides and Their $\mathrm{O}$ [Single Bond] $\mathrm{O}$ Bond Dissociation Energies. Chem Phys1964; 40:1007.

[39] Ginhac JM, Gardette JL, Arnaud R, Lemaire J, Makromol Chem1981; 182:1017.

[40] Lacoste J, Carlsson DJ. Polym Sci, Polym Chem. Ed (in press) 1992.

[41] Decker C, Mayo FR, Richardson HJ. Polym Sci. Polym. Chem. Ed 1973; 11.p .2879.

[42] Carlsson DJ, Chmela S, Wiles DM. Polym Deg Stab1991; 31. P. 255.

[43] Sitek F, Guillet JE, Heskins M. Polym Sci. Symp Ser 1976 ; 57. P. 343.

[44] Guillet JE. Polymer Photophysics and Photochemistry. Cambridge University Press, Cambridge, 1985.

[45] Verdu J, Le vieillissement des plastiques, Ed. AFNOR. Paris, 1984.

[46] Wu S, Ji G, Shen J. A study on ultraviolet irradiation modification of high-density polyethylene and its effect in the compatibility of HDPE/PVA fibre composites. Materials Letters. 2003; 57(18):2647-2650.

[47] Rabek FJ. Photodegradation of Polymers. Phys Charact Appl. Berlin: Springer, 1996.

[48] Liu M, Horrocks AH, Hall ME. Correlation of physicochemical changes in UV-exposed LDPE films containing various UV stabilizers. PolymDegrad Stab1995; 49:151-161.

[49] Dilara PA, Briassoulis D. Degradation and stabilization of low density polyethylene (LDPE) films used as greenhouse covering materials. Agric Eng Res 2000; 76:309-321. 